\title{
Superimposed visceral leishmanial infection aggravates response to Heligmosomoides polygyrus
}

\author{
M. E. González-Sánchez ${ }^{1,2}$, M. Cuquerella $a^{1,2}$ and J. M. Alunda $a^{1,2^{*}}$
}

\begin{abstract}
Background: Polyparasitism is the rule in all animal species, including humans, and has an important role in pathogenicity, diagnosis and control measures. Among them, co-infections by gastrointestinal helminths and protists are very prevalent under natural conditions but experimental infections are relatively scarce. Thus, despite the frequent association of visceral Leishmania infections and intestinal helminth parasitism the experimental co-infection has not been addressed. Heligmosomoides polygyrus, an intestinal nematode of mice, is related to other helminths causing important pathologies and is a model species for immunological studies. Mice are valuable experimental model for visceral leishmaniasis.
\end{abstract}

Methods: BALB/c mice infected with H. polygyrus (200 third-stage larvae, L3) were subsequently infected seven days later with Leishmania infantum ( $10^{7}$ promastigotes) with the aim of determining the effect of the overinfection on the host response to the primary infection with the helminth.

Results: Overinfection with the protist did not affect the establishment rate of the nematode but induced a higher fecal egg output. Helminth burdens in co-infected animals were significant at the end of the experiment. Early unspecific immune suppression induced by the nematode in mesenteric lymph nodes was not switched by L. infantum infection. Co-infection elicited a higher serum antibody $\left(\operatorname{lgG}_{1}\right)$ response against the helminth.

Conclusions: Visceral leishmanial overinfection aggravated the early host response against primary infections with the intestinal helminth. This effect was evidenced by an increased longevity and higher production of non-protective antibodies.

Keywords: Heligmosomoides polygyrus, Leishmania infantum, Co-infections, $\lg G_{1}, \lg G_{2 a}$, Lymphoproliferation, ELISA, $\mathrm{BALB} / \mathrm{c}$ mice, Helminth

\section{Background}

Gastrointestinal nematodiases are a major problem worldwide, both for human and animal health. Helminth infections are present in all species of wild and domestic animals, with different management practices and climates. Soil-transmitted helminthiases (STHs) are among the most common and persistent parasitic infections worldwide and it has been estimated that over three billion people are infected with one or more helminth species [1]. In the veterinary arena these diseases have a strong impact on health

\footnotetext{
* Correspondence: jmalunda@ucm.es

${ }^{1}$ Department of Animal Health, Faculty of Veterinary Medicine, Universidad Complutense de Madrid, 28040 Madrid, Spain

${ }^{2}$ Instituto de Investigación Hospital Doce de Octubre, Avda. Andalucía s/n, 28041 Madrid, Spain
}

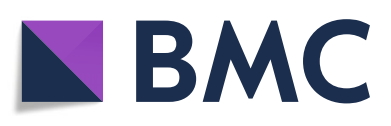

(c) The Author(s). 2018 Open Access This article is distributed under the terms of the Creative Commons Attribution 4.0 International License (http://creativecommons.org/licenses/by/4.0/), which permits unrestricted use, distribution, and reproduction in any medium, provided you give appropriate credit to the original author(s) and the source, provide a link to the Creative Commons license, and indicate if changes were made. The Creative Commons Public Domain Dedication waiver (http://creativecommons.org/publicdomain/zero/1.0/) applies to the data made available in this article, unless otherwise stated. status, productivity and therefore on the sustainability of animal production. Visceral leishmaniasis is the second most lethal parasitic disease for humans [2]. Leishmania infantum zoonotic infection is found in the Mediterranean and Brazil where millions of dogs are naturally infected.

Multiparasite infections are the rule and the coexistence of more than one species in a host has significant effects on their pathogenicity, clinical course and design of control systems [3, 4]. Information is relatively scarce and only recently has a growing interest on the study of multiparasitism been observed $[5,6]$.

Heligmosomoides polygyrus (Nematoda: Strongylida), a natural parasite of mice intestines, is a species taxonomically related to those causing processes of relevance in 
humans (e.g. Necator, Ancylostoma) and in animal health and production (e.g. Ostertagia, Haemonchus). Primary exposure to $H$. polygyrus provokes a predominant Th2 response [7] accompanied by regulatory $\mathrm{T}$ cell (Treg) activation, thus failing to achieve an effective expulsion of the worms and causing chronic infections in most mouse strains [8-10]. The lack of protective response in primary infections is related to the immunosuppressive abilities of the nematode since an effective response appears when the primary infection is cleared (i.e. with drug treatment) [11]. Immune interference between helminths and protozoans has been described and experimentally addressed in some combinations [12-16]. Cross-sectional studies have been carried out in human patients with cutaneous (caused by Leishmania braziliensis) [17] and visceral leishmaniasis [18] and helminth infections with conflicting results. However, the potential effect of a visceral Leishmania infection on previously infected hosts with intestinal helminths has apparently not been experimentally addressed. This lack of information is surprising, given the widespread distribution of helminths all over the world and the high prevalence of visceral leishmanial infections. Since $H$. polygyrus infections are a well established model of Th2 response in mice and $L$. infantum infection in mice elicits a mixed Th1/Th2 response [19-21], we administered an overinfection with L. infantum to BALB/c mice previously infected with $H$. polygyrus. Results obtained in this surrogate model showed that visceral leishmanial infection aggravated the primary response against the intestinal helminth.

\section{Methods}

\section{Parasites}

Heligmosomoides polygyrus larvae were provided by $\mathrm{M}$. Grueiro (Faculty of Pharmacy, UCM, Madrid, Spain) and the isolate was maintained in our laboratory by passage in susceptible mice every 6 months. The infective thirdstage larvae (L3) were obtained by incubation of fecal material on filter paper disks placed on a Petri dish with distilled water at $22{ }^{\circ} \mathrm{C}$ for 7 days. The isolate of $L$. infantum (M/CAN/ES/97/10.445 zymodeme MON-1) was supplied by M. Domínguez (ISCIII, Madrid, Spain) and has been maintained as promastigotes by passage in RPMI 1640 medium (Lonza Group, Basel, Switzerland) at $26{ }^{\circ} \mathrm{C}$ supplemented with heat inactivated fetal bovine serum $\left(30 \mathrm{~min}, 56{ }^{\circ} \mathrm{C}\right.$ ) (Sera Laboratories International, Horsted Keynes, UK) and $100 \mathrm{U} / \mathrm{ml}$ penicillin $+100 \mu \mathrm{g} / \mathrm{ml}$ streptomycin (BioWhittaker, Verviers, Belgium).

\section{Mice, experimental design and follow-up}

Female BALB/c mice (Harlan Laboratories Models SL, Barcelona, Spain) were housed in our facilities (No. ES280790000155) in polystyrene cages (4 animals per cage) at a controlled temperature of $22-25^{\circ} \mathrm{C}$ with a $12 \mathrm{~h}$ light $12 \mathrm{~h}$ darkness cycle and received water and commercial rodent feed ad libitum. Mice were randomly allocated to four experimental groups of eight animals per group. G1 and G2 animals were infected with $200 \mathrm{~L} 3$ of $H$. polygyrus in $0.2 \mathrm{ml}$ water, using a bucoesophagic catheter, on day 0 of the experiment. G1 and G3 animals were infected by intraperitoneal injection, on day 7 post-infection (pi), with $10^{7}$ stationary promastigotes of L. infantum in $0.1 \mathrm{ml}$ PBS. G4 was the uninfected control group.

Individual blood samples were obtained on day $-1,6$, 14, 21, 28 and 35 pi with $H$. polygyrus by puncture of submandibular vein. The blood volume obtained was 50 $\mu \mathrm{l} /$ mouse/sample day except for the days when animals were euthanatized (14 and $35 \mathrm{pi}$ ) when $150 \mu \mathrm{l}$ were taken. Blood was allowed to clot and the sera preserved at $-20{ }^{\circ} \mathrm{C}$ until used. Samples taken at the end point of the experiment were employed for ELISA determinations. Coproscopical analyses were performed every 3 days from the 9th day pi onwards. Mice were individually isolated for $30 \mathrm{~min}$, their feces collected and egg counts performed by a modified flotation technique. The results were expressed as eggs per gram of feces (epg). Cumulative epg output was estimated using the trapezoidal method to determine areas under the curve (AUC) of the animals and groups. Mice were euthanatized $\left(\mathrm{CO}_{2}\right.$ inhalation - isoflurane) on days 14 and $35 \mathrm{pi}, 4$ animals per group at each time point. Intestines, spleens and mesenteric lymph nodes were removed and employed for further determinations. Individual intestines were opened and placed in physiological saline solution, kept overnight at $37{ }^{\circ} \mathrm{C}$ and the worms were recovered and counted. Spleens were extracted under sterile conditions and weighed individually. To assess $L$. infantum infection, a spleen sample was employed to prepare smears, stained with May Grünwald Giemsa and microscopically examined.

\section{Antigens}

Heligmosomoides polygyrus soluble extract (ASE) was obtained from adult helminths. Nematodes were cleaned with cold PBS containing protease inhibitors (Roche, Mannheim, Germany), subjected to 8 freeze-thaw cycles $\left(-80{ }^{\circ} \mathrm{C}\right.$ to room temperature), homogenized in a glassin-glass homogenizer and centrifuged at $3000 \times g$ for 30 min at $4{ }^{\circ} \mathrm{C}$. Soluble leishmanial antigen (SLA) was obtained by 10 freeze-thaw cycles of $L$. infantum promastigotes followed by centrifugation and recovery of the supernatant. The concentration of protein was measured [22] and the antigen extracts (SLA, ASE) stored at $-80^{\circ}$ $\mathrm{C}$ until use.

\section{Lymphoproliferation}

Lymphocyte proliferation was determined using the tetrazolium salt (MTT) method [23] with some modifications. 
Mesenteric lymph nodes (MLN) and spleen were dissected individually and homogenized in medium RPMI 1640. The suspension was filtered $(100 \mu \mathrm{m}$ mesh), centrifuged at $300 \times \mathrm{g}, 10 \mathrm{~min}, 4{ }^{\circ} \mathrm{C}$ and the pellet resuspended in medium with $10 \%$ fetal bovine serum, 100 $\mathrm{U} / \mathrm{ml}$ of penicillin $+100 \mu \mathrm{g} / \mathrm{ml}$ streptomycin and $1 \%$ glutamine. Erythrocytes were lysed with red blood cells lysis buffer $\left(0.15 \mathrm{M} \mathrm{NH} \mathrm{NH}_{4} \mathrm{Cl} 10 \mathrm{mM} \mathrm{KHCO}_{3}+0.1 \mathrm{M}\right.$ $\mathrm{Na}_{2}$ EDTA, pH7.2). The viability was assessed with Trypan blue. Viable cells from MLN $\left(2 \times 10^{6}\right.$ cells $\left./ \mathrm{ml}\right)$ and spleen $\left(5 \times 10^{6}\right.$ cells $\left./ \mathrm{ml}\right)$ were seeded in 96-well flat bottomed plates (Corning, Corning, USA; $200 \mu \mathrm{l} /$ well) and stimulated with Concanavalin A (GE Healthcare, Madrid, Spain; $5 \mu \mathrm{g} / \mathrm{ml})$, SLA and ASE $(5 \mu \mathrm{g} / \mathrm{ml}$ for MLN; $10 \mu \mathrm{g} / \mathrm{ml}$ for spleen). The cells were incubated for $96 \mathrm{~h}$ at $37{ }^{\circ} \mathrm{C}$ in a humidified atmosphere of $5 \%$ $\mathrm{CO}_{2}$. Proliferation was determined by adding $50 \mu \mathrm{l}$ MTT $(5 \mathrm{mg} / \mathrm{ml})$ (Sigma, St. Louis, USA) $+200 \mu \mathrm{l}$ culture medium for $4 \mathrm{~h}$ at $37^{\circ} \mathrm{C}$. Absorbance was read at $570 \mathrm{~nm}$. All determinations were performed in triplicate and negative controls were included. Results were expressed as stimulation index (SI): optical density (OD) of stimulated cell cultures/OD of unstimulated control wells. SI $\geq 1.5$ were considered positive.

\section{Enzyme linked immunosorbent assay (ELISA)}

Serum specific antibody response $\left(\mathrm{IgG}_{1}\right.$ and $\left.\mathrm{IgG}_{2 \mathrm{a}}\right)$ was determined by ELISA. Optimal assay conditions were determined in a checkerboard manner. Briefly, microtitre plates (Nunc, Roskilde, Denmark) were coated with $5 \mu \mathrm{g} /$ $\mathrm{ml}$ ASE or SLA. Anti-mouse $\mathrm{IgG}_{1}$-HRP was from Nordic Immunology (Eindhoven, Netherlands) and HRP anti-IgG was from Southern Biotech (Birmingham, USA). Mice sera were diluted $1 / 800$ and conjugate $1 / 2500$ to determine $\mathrm{IgG}_{1}$ against ASE; $1 / 50$ sera dilution and $1 / 1000$ conjugate dilution to estimate anti-SLA response. $\mathrm{IgG}_{2 \mathrm{a}}$ against ASE employed sera diluted $1 / 400$ and $1 / 2000$ dilution conjugate. Anti-Leishmania $\operatorname{IgG}_{2 a}$ was determined with $1 / 25$ sera dilution and 1/2000 conjugate.

\section{Statistical analysis}

Intergroup differences were analyzed by t-test (adult helminthes, epg) or 2-way ANOVA (epg, spleen weight, lymphoproliferative response, ELISA results) followed by Tukey's HSD test. Exact $P$-values, degrees of freedom $(d f)$ and analysis carried out are given using the APA format. The level of significance was set at $P<0.05$. Figures were prepared with Graphpad Prysm 5.

\section{Results}

Overinfection with $L$. infantum provokes higher fecal egg output of $H$. polygyrus-infected mice

Animal groups infected with $H$. polygyrus (G1 and G2) started eggs excretion on day $10 \mathrm{pi}$; however, the epg pattern greatly varied depending on the infections received (Fig. 1). There was a high intragroup individual variability within a sample day and along the experiment. Thus, cumulative egg excretion, estimated by AUC from day 15 to the end of the experiment, showed that mice infected only with $H$. polygyrus shed $c .25 \%$ of the AUC value of co-infected mice (G1: H. polygyrus $+L$. infantum) although the difference was not significant. There was a different pattern of epg values between animal groups and egg excretion (AUC) of co-infected mice was significantly higher between days 15 and $21 \mathrm{pi}\left(t_{(6)}=2.342\right.$, $P=0.0288)$. No eggs were found in the mice infected only with L. infantum (G3) and the uninfected control group.

\section{Leishmania infantum overinfection does not affect establishment of $H$. polygyrus although it increases helminth survival}

On day $14 \mathrm{pi}$, estimated total worm burden was comparable in both mice groups (G1: 86.25 and G2: 88.25 helminths) and no differences were found in sex ratio of helminths (Fig. 2). Conversely, 35 days pi parasite burdens were significantly different depending on the presence of concurrent $L$. infantum infection. In a similar way to that found in epg patterns, mice co-infected (G1) hosted higher worm burdens than those observed in animals subjected only to $H$. polygyrus infection $\left(t_{(6)}=2.188\right.$, $P=0.0357)$. The sex ratio of the adult population at the end-point varied according to the life-cycle of the helminth with a predominant female population (c.70\%) in both animal groups.

\section{Spleen enlargement of co-infected mice relates to $H$. polygyrus infection}

There were significant differences among groups depending on the infection schedule $\left(F_{(3,24)}=56.85, P<0.0001\right)$,

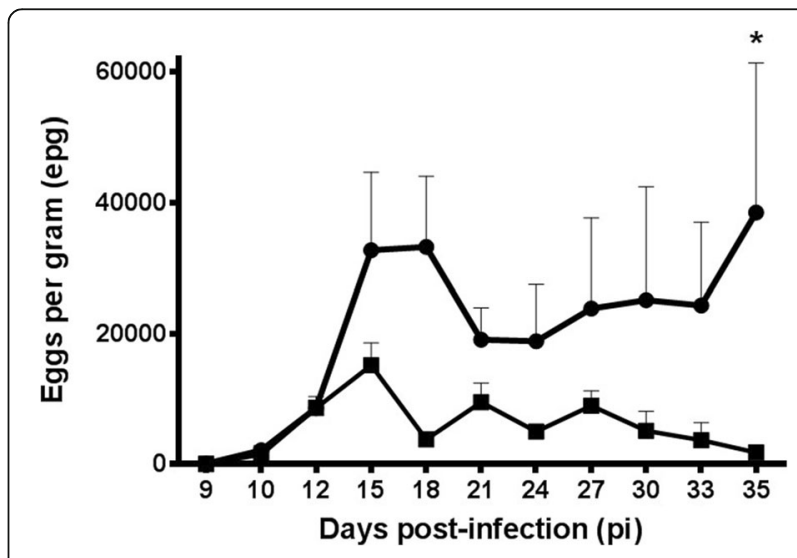

Fig. 1 Heligmosomoides polygyrus egg excretion (eggs per gram, epg; mean $\pm \mathrm{SE}$ ) in infected mice with (G1, circles) or without superimposed Leishmania infantum infection (G2, squares).* $P<0.05$ 


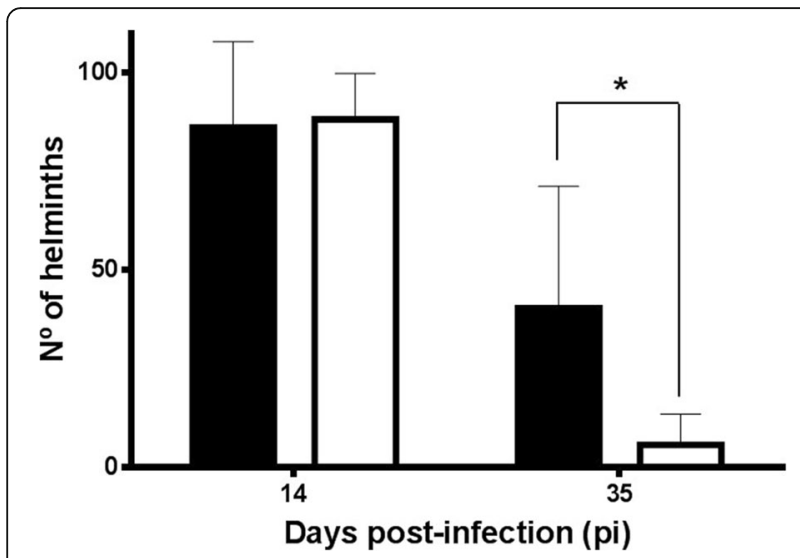

Fig. 2 Intestinal helminth burden (mean \pm SE) of H. polygyrus-infected mice with (G1) or without (G2) L. infantum overinfection. Solid bars, G1; empty bars, G2. ${ }^{*} P<0.05$

time of sampling $\left(F_{(1,24)}=46.20, P<0.0001\right)$ and the interaction $\left(F_{(3,24)}=8.482, P=0.0005\right)$ (Fig. 3). Tukey's analysis showed that infection with $H$. polygyrus induced a significant splenomegaly of the animals since the spleen weights found in the group infected only with the nematode (G2) were significantly higher than those found in the group infected with $L$. infantum (G3) and the uninfected control group (G4) in the two samplings carried out (days 14 and $35 \mathrm{pi}$ ). This finding was particularly clear on day 14 of the experiment when the mean spleen weight found in the mice infected only with $H$. polygyrus was 2.64 times higher than that found in the control group (mean \pm SD; G2: $0.2565 \pm$ 0.0390; G4: $0.0973 \pm 0.0112$ ). In our experimental conditions $L$. infantum infection

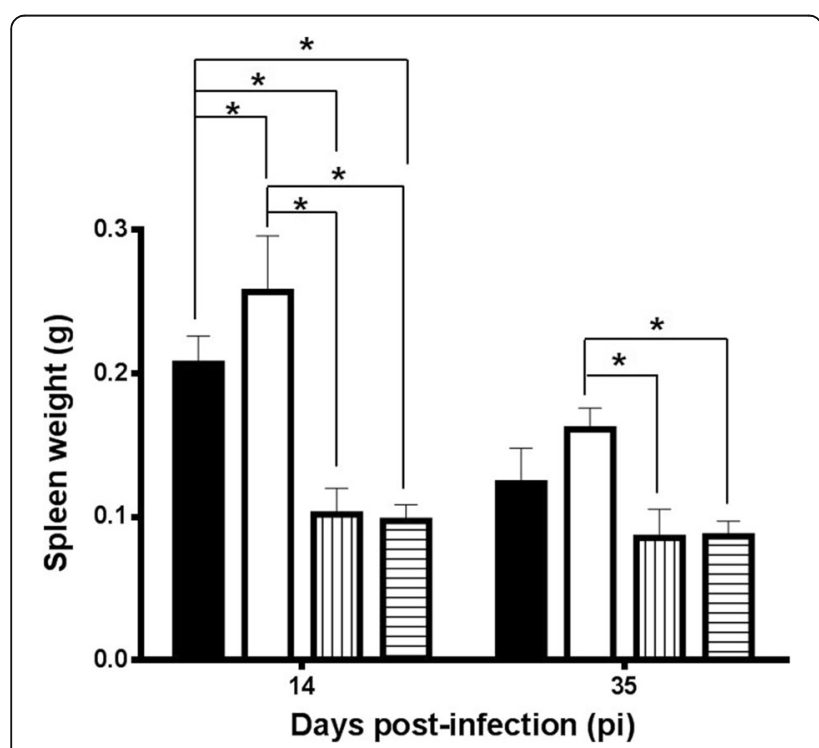

Fig. 3 Spleen weight (mean \pm SD) from mice at early patency (14 days pi) and the end of the experiment (35 days pi). Solid bars, G1; empty bars, G2; vertical striped bars, G3; horizontal striped bars, G4. * $P<0.05$ did not elicit any significant increase in spleen size. Spleen enlargement was found in all groups infected with the nematode. However, overinfection of $H$. polygyrus-infected mice with L. infantum (G1) induced a slight reduction of spleen weight at the beginning of the patency (day 14) (G1: $0.2066 \pm 0.0193)$ when compared to mice only subjected to the helminth infection (G2: $0.2565 \pm 0.0390)$.

Early unspecific immune suppression elicited by $\mathrm{H}$. polygyrus is not switched by $L$. infantum overinfection Infections by both $L$. infantum and $H$. polygyrus elicited unspecific immunosuppression as assessed by the lower lymphoproliferation found in mesenteric lymph nodes (MLN) (Fig. 4a; $F_{(3,24)}=4.096, P=0.018$ ) and spleen (Fig. 4b; $F_{(3,24)}=3.753, P=0.024$ ) at both time-points when cells were exposed to ConA. However there were infection- and time-course-related variations. Thus, in MLN an early immune suppression was more evident in the presence of $H$. polygyrus infection (G1: $2.590 \pm$ 2.550; G2: $7.854 \pm 7.554$ ) compared to the uninfected mice (G4: $155.273 \pm 76.266$ ). A partial restoration was observed after 35 days of infection and at this time-point mice infected only with $H$. polygyrus (G2) were not significantly different to uninfected control animals. This early immune suppression was also observed with spleen cells. In the case of L. infantum, infection immune suppression followed a different pattern. Thus, on day 35 only mice infected with this parasite (G3: $6.264 \pm 10.638)$ and to a lesser extent the co-infected group (G1: $83.390 \pm$ 54.134) had significantly lower lymphoproliferative values than the control animals $(233.145 \pm 70.318)$. These results were particularly clear with MLN cells although the pattern was also found with spleen cells.

Specific lymphoproliferation in MLN (Fig. 5a) and spleen (Fig. 5b), in the presence of $H$. polygyrus soluble antigen was low in all groups. Despite the helminth-induced unspecific suppression, the most reactive animals in MLN were those co-infected with $L$. infantum $\left(F_{(2,18)}\right.$ $=8.762, P=0.002]$ with significant differences on day 14 $(2.181 \pm 0.251)$ to both the control group $(1.032 \pm$ $0.376)$ and the animals with monospecific helminth infection $(0.904 \pm 0.104)$. This pattern was also observed after 35 days although differences were not significant. In the spleen (Fig. 5b) co-infected mice (G1) also displayed a higher proliferative response in the last sampling (1.474 \pm 0.365). Lymphoproliferative response against leishmanial antigen was low and not related to the infection schedule of the animal groups (not shown).

\section{Overinfection with $L$. infantum increased the antibody response to $H$. polygyrus}

Antibody response against $H$. polygyrus was slow to develop and on day 35 pi showed a significant $\operatorname{IgG}_{1}$ serum 

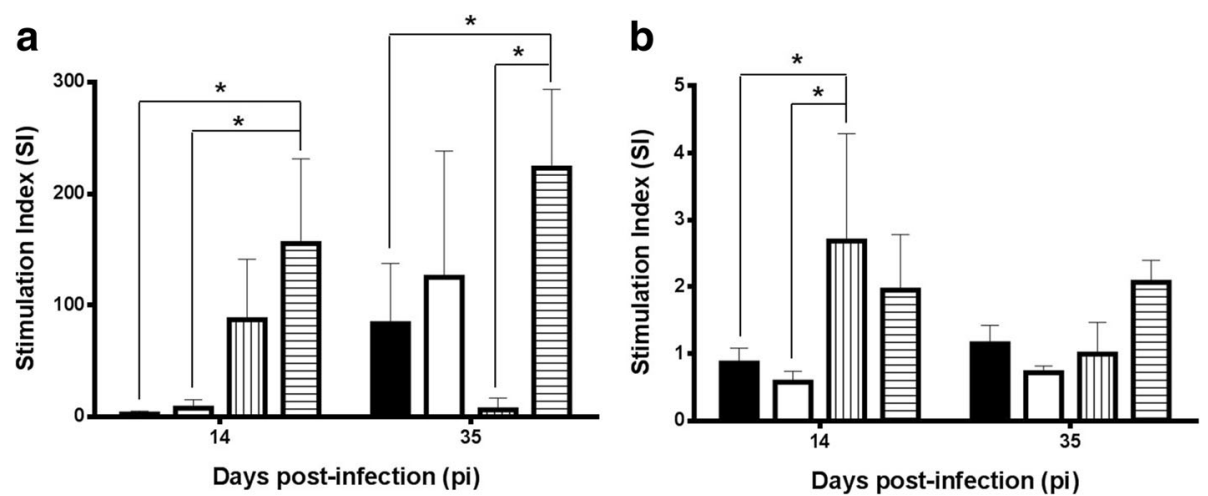

Fig. 4 Lymphoproliferative response (mean stimulation index, $\mathrm{SI} \pm \mathrm{SD}$ ) in the presence of Con A in mesenteric lymph nodes (a) and spleen (b) on days 14 and 35 pi. Solid bars, G1; empty bars, G2; vertically striped bars, G3; horizontally striped bars, G4. ${ }^{*} P<0.05$

response against Heligmosomoides ASE in the groups infected with the helminth (Fig. 6a) $\left(F_{(3,24)}=37.939\right.$, $P<0.0001]$. The response was higher in the group co-infected (G1: $0.362 \pm 0.098)$ than in the mice with monospecific infection (G2: $0.311 \pm 0.054)$ although differences were not significant. No specific $\mathrm{IgG}_{2 \mathrm{a}}$ response to Heligmosomoides ASE was observed except for an outlier value (Fig. 6b). Monospecific Leishmania infection (G3) elicited a significant IgG apparently related to the $\mathrm{IgG}_{2 \mathrm{a}}$ response (35 days pi) against homologous antigen extract (SLA) whereas no $\mathrm{IgG}_{1}$ specific response was observed (not shown).

\section{Discussion}

Under natural conditions, co-infections are the rule in all host species, including humans, [3] and they have a significant impact on disease course outcome, diagnosis and preventive measures [6]. Helminth-protist interactions are very complex ranging from a lack of interference [14] to strong impairment of protective immunity [13]. For the most part, some type of modulation/switching of immune response has been found in the co-infections so far explored. Direct comparison of the results is extremely difficult since the mechanisms involved and final outcome depend on the parasite species and also the schedule of infections (e.g. timing and doses administered). In our experiments, overinfection with $L$. infantum of previously infected mice with $H$. polygyrus strongly impaired the immune response against helminth infection. This interference was evidenced by a worsening of major parameters such as the apparent higher fertility of female worms in early patency and higher helminth burdens at the end of the experiment.

The number of helminths found at the beginning of the patency evidenced a high establishment rate (c.40\%), in-line with previous observations in primary infections by $H$. polygyrus $[24,25]$. It has been reported that a previous infection with Toxoplasma gondii led to a higher fecundity of $H$. polygyrus female worms 14 days pi [26]. These results were comparable to those obtained by us with an unrelated protist species, L. infantum. Thus, a notable increase in fecal egg output was found in co-infected mice from day 15 to 21 pi without helminth number differences compared to the animals subjected
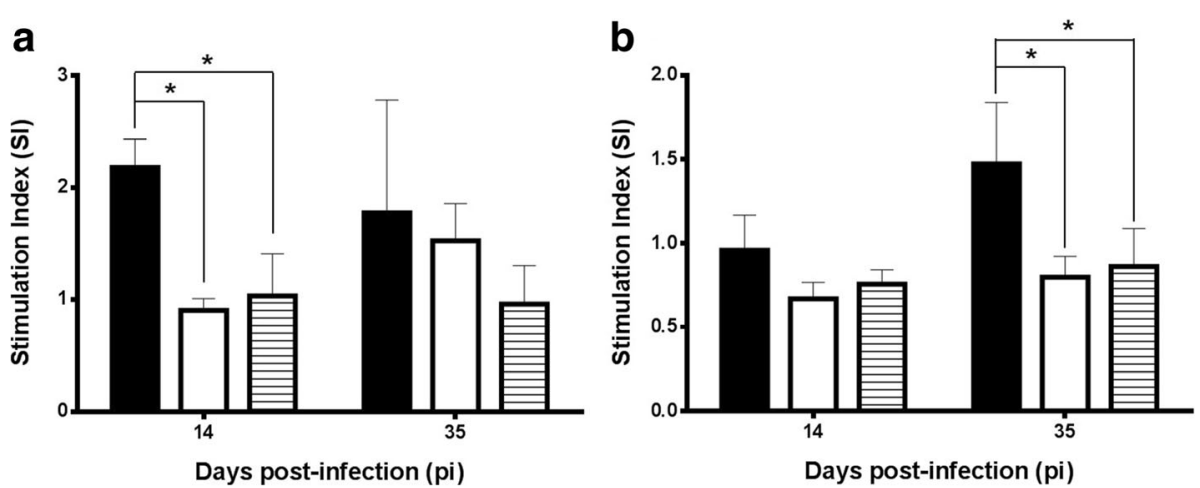

Fig. 5 Specific lymphoproliferative response (mean stimulation index, SI \pm SD) to adult soluble extract of $H$. polygyrus in mesenteric lymph nodes (a) and spleen (b). Solid bars, G1; empty bars, G2; horizontally striped bars, G4. *P 0.05 



Fig. 6 Individual serum $\lg G_{1}(\mathbf{a})$ and $\lg G_{2 a}$ (b) levels of experimental mice on days 14 and 35 pi against $H$. polygyrus adult soluble extract (ASE) estimated by ELISA. Solid circles, G1; solid squares, G2; solid triangles, G4. ${ }^{*} P<0.001$

to a single $H$. polygyrus infection (14 days pi). Moreover, we found at the end of the experiment (35 days pi) a significantly higher number of worms in co-infected mice. These findings are consistent with the partial abrogation of the Th2 response in $H$. polygyrus infections [10] and it has also been described in other co-infections with this helminth species $[16,26]$ irrespective of the experimental design. In $H$. polygyrus/ Trypanosoma congolense co-infections, no differences were found in female helminth fertility [24, 27]. However, this experiment was not designed to determine the response in primary helminth infections but the acquired resistance after challenge. Our results suggest that the timing, order and protist species involved is apparently less relevant and in both cases immune response polarizes towards a Th1 type this resulting in both higher fecundity and longevity of helminths. The actual mechanistic basis of this interference is poorly known and deserves attention since it is much relevant within the framework of naturally infected hosts where the polyparasitism is the rule [5].

Single infection with $L$. infantum did not elicit significant changes in spleen weight in any of the experimental time points ( 1 week pi, 4 weeks pi). Intravenous infection of susceptible mice (e.g. BALB/c) with visceral Leishmania leads to self-limiting liver invasion and a progressive spleen parasitism. Thus, our results could be possibly related to the pi time elapsed [28]. Mice infected with $H$. polygyrus alone or co-infected with $L$. infantum showed a notable increase in spleen weight, this being consistent with the immune response mounted against the nematode infection. It is noteworthy to indicate that co-infection with $L$. infantum actually caused an early reduction of spleen weights (14 days pi) compared to those seen in the mice with the helminth infection alone. This result supports the interference of the co-infection and the impairment of the characteristic Th2 protective response against the nematode $[8,29]$. Poor anti- $H$. polygyrus specific lymphoproliferation in both lymph nodes and spleen was consistent with the unspecific immune suppression (ConA) elicited by nematode infection, particularly in the first parasitic stages ( $<14$ days pi). Conversely, the immune suppression in L. infantum-infected mice (G3) was seen in later stages (day 35 pi), perhaps related to the course of the infection [28]. Visceral Leishmania infections cause a mixed Th1/Th2 response [19-21] and $H$. polygyrus is highly effective in blocking the protective Th2 immunity [10]. In our experiment with primary helminth infections, high $\operatorname{IgG}_{1}$ anti- $H$. polygyrus levels were found after 35 days whereas no $\operatorname{IgG}_{2 a}$ was detected. This suggests a Th2 polarized response [29] and, in our experiment, $L$. infantum overinfection actually increased the antibody response against the helminth. A lack of correlation between $\operatorname{IgG}_{1}$ levels and protection (e.g. reduced parasite burden or fecal egg output) points towards the limited protective role of the antibodies detected by ELISA [30]. Although not strictly comparable to our experimental approach, it has been observed that human patients co-infected with visceral Leishmania and helminths displayed no alteration of the course of leishmaniasis [19] whereas the clinical outcome of cutaneous infection by L. braziliensis was significantly influenced by helminth co-infection [17]. It is possible that the initial clinical condition of patients, chemotherapeutic regimen, differential immune response against visceral and cutaneous Leishmania and the timing of infections (protist, helminth) could account for the variable response observed.

\section{Conclusions}

Considering all results together, our experiment confirmed the unspecific and specific immune suppression elicited by primary infection by $H$. polygyrus in mice. More importantly, overinfection with $L$. infantum of previously infected animals with the helminth aggravated the suppression, leading to higher parasite burdens, fecal egg output and 
longevity. Co-infection apparently polarized the immune response towards a non-protective Th1 type. However, no complete Th1/Th2 switch was found since co-infected mice developed a notable specific $\mathrm{IgG}_{1}$ response against Heligmosomoides. A lack of correlation between protection and $\operatorname{IgG}_{1}$ levels suggests the limited role played by antibodies in coping with helminth infection.

\section{Abbreviations}

PBS: phosphate-buffered saline; ELISA: enzyme-linked immunosorbent assay; EPG: eggs per gram; AUC: area under the curve; pi: post-infection; ASE: adult soluble extract; SLA: soluble leishmanial antigen; MTT: 3-(4,5-dimethylthiazol2-yl)-2,5-diphenyltetrazolium bromide; EDTA: ethylenediaminetetraacetic acid; MLN: mesenteric lymph nodes; SD: standard deviation; SE: standard error; HSD: honestly significant difference

\section{Acknowledgements}

The authors thank the kind donation of H. polygyrus larvae by M. Grueiro (Faculty of Pharmacy, UCM) and L. infantum promastigotes culture by M. Domínguez (ISCIII, Madrid)

\section{Funding}

The authors thank the partial financial support by MINECO grant AGL2014-54049-R.

\section{Availability of data and materials}

All data corresponding to the results obtained in the experiments described are available from the authors.

\section{Authors' contributions}

MC and JMA conceived and designed the study. MC and MEGS performed the experiments. MC, MEGS and JMA discussed the results. JMA wrote the manuscript. All authors read and approved the final manuscript.

\section{Ethics approval and consent to participate}

Experimental design and procedures were approved by the Ethical Committee (UCM) and Regional authorities (Comunidad de Madrid) (PROEX 169/15).

\section{Consent for publication}

Not applicable.

\section{Competing interests}

The authors declare that they have no competing interests.

\section{Publisher's Note}

Springer Nature remains neutral with regard to jurisdictional claims in published maps and institutional affiliations.

Received: 17 January 2018 Accepted: 2 July 2018

Published online: 11 July 2018

\section{References}

1. Hotez PJ, Brindley PJ, Bethony JM, King CH, Pearce EJ, Jacobson J. Helminth infections: the great neglected tropical diseases. J Clin Invest. 2008;118:1311-21.

2. Pace D. Leishmaniasis. J. Infection. 2014;69:S10-8.

3. Petney TN, Andrews RH. Multiparasite communities in animals and humans: frequency, structure and pathogenic significance. Int J Parasitol. 1998;28:377-93.

4. Moreau M, Chauvin A. Immunity against helminths: interactions with the host and the intercurrent infections. J Biomed Biotechnol. 2010;2010:428593.

5. Griffiths EC, Pedersen AB, Fenton A, Petchey OL. Analysis of a summary network of co-infection in humans reveals that parasites interact most via shared resources. Proc Biol Sci. 2014;281:20132286

6. Vaumourin E, Vourc'h G, Gasqui P, Vayssier-Taussat M. The importance of multiparasitism: examining the consequences of co-infections for human and animal health. Parasit Vectors. 2015:8:545.

7. Wahid FN, Behnke JM, Grencis RK, Else KJ, Ben-Smith AW. Immunological relationships during primary infection with Heligmosomoides polygyrus: Th2 cytokines and primary response phenotype. Parasitology. 1994;108:461-71.
8. Reynolds LA, Filbey KJ, Maizels RM. Immunity to the model intestinal helminth parasite Heligmosomoides polygyrus. Semin Immunopathol. 2012;34:829-46.

9. Doligalska M, Rzepecka J, Drela N, Donskow K, Gerwl-Wronka M. The role of TFG- $\beta$ in mice infected with Heligmosomoides polygyrus. Parasite Immunol. 2006:28:387-95

10. Maizels RM, Hewitson JP, Murray J, Harcus YM, Dayer B, Filbey KJ, et al. Immune modulation and modulators in Heligmosomoides polygyrus infection. Exp Parasitol. 2012;132:76-89.

11. Valanparambil RM, Tam M, Jardim A, Geary TG, Stevenson MM. Primary Heligmosomoides polygyrus bakeri infection induces myeloid-derived suppressor cells that suppress CD4 ${ }^{+}$Th2 responses and promote chronic infection. Mucosal Immunol. 2017;10:238-49.

12. Rousseau D, Le Fichoux Y, Stien X, Suffia I, Ferrua B, Kubar J. Progression of visceral leishmaniasis due to Leishmania infantum in BALB/C mice is markedly slowed by prior infection with Trichinella spiralis. Infect Immun. 1997:65:4978-83.

13. Su Z, Segura M, Morgan K, Loredo-Osti JC, Stevenson MM. Impairment of protective immunity to blood-stage malaria by concurrent nematode infection. Infect Immun. 2005;73:3531-9.

14. Kolbaum J, Ritter U, Zimara N, Brewig N, Eschibach ML, Breloer M. Efficient control of Leishmania and Strongyloides despite partial suppression of nematode-induced Th2 response in co-infected mice. Parasite Immunol. 2011:33:226-35.

15. Kelada S, Sethupathy P, Okoye IS, Kistasis E, Czieso S, White SD, et al. miR-182 and miR-10a are key regulators of Treg specialisation and stability during schistosome and Leishmania-associated inflammation. PLoS Pathog. 2013;9:e1003451.

16. Coomes SM, Pelly VS, Kannan Y, Okoye IS, Czieso S, Entwstle LJ, et al. INFY and IL-12 restrict Th2 responses during helminth/Plasmodium co-infection and promote IFNy from Th2 cells. PLoS Pathog. 2015;11:e0004994.

17. O'Neal SE, Guimarães LH, Machado PR, Alcântara L, Morgan DJ, Passos S, et al. Influence of helminth infections on the clinical course of and immune response to Leishmania braziliensis cutaneous leishmaniasis. J Infect Dis. 2007;195:142-8.

18. Tajebe F, Getahun M, Adem E, Hailu A, Lemma M, Fikre H, et al. Disease severity in patients with visceral leishmaniasis is not altered by co-infection with intestinal parasites. PLoS Negl Trop Dis. 2017;11:e0005727.

19. Honoré S, Grain YJ, Sulahian A, Gangneux JP, Derouin F. Influence of the host and parasite strain in a mouse model of visceral Leishmania infantum infection. FEMS Immunol Med Microbiol. 1998:21:231-9.

20. Rolão N, Cortes S, Gomes-Pereira S, Campino L. Leishmania infantum: mixed T-helper-1/T-helper-2 immune response in experimentally infected BALB/C mice. Exp Parasitol. 2007;115:270-6.

21. Loeuillet C, Bañuls AL, Hide M. Study of Leishmania pathogenesis in mice: experimental considerations. Parasit Vectors. 2016:9:144.

22. Bradford MM. A rapid and sensitive method for the quantitation of microgram quantities of protein utilizing the principle of protein-dye binding. Anal Biochem. 1976;72:248-54.

23. Plumb JA. Cell sensitivity assays: the MTT assay. Methods Mol Med. 2004;88:165-9.

24. Fakae BB, Harrison LJ, Ross CA, Sewell MM. Expression of acquired immunity to Heligmosomoides polygyrus in mice concurrently infected with Trypanosoma congolense. Int J Parasitol. 1997:27:1107-14.

25. González-Sánchez E, Corral MJ, Fawzi EM, Rodríguez-Bertos A, Alunda JM, Cuquerella M. LPS and inactivated Propionibacterium acnes elicit a partially protective response in primary infections of Heligmosomoides polygyrus. Vet Parasitol. 2014;203:231-6.

26. Ahmed N, French T, Rausch S, Kühl A, Hemminger K, Dunay IR, et al. Toxoplasma co-infection prevents Th2 differentiation and leads to a helminth-specific Th2 response. Front Cell Infect Microbiol. 2017:7:341.

27. Fakae BB, Harrison LJ, Ross CA, Sewell MMH. Heligmosomoides polygyrus and Trypanosoma congolense infection in mice: a laboratory model for concurrent gastrointestinal nematode and trypanosome infections. Parasitology. 1994:108:61-8.

28. Bankoti R, Stäger S. Differential regulation of the immune response in the spleen and liver of mice infected with Leishmania donovani. J Trop Med. 2012:2012:639304

29. Finney CA, Taylor MD, Wilson MS, Maizels RM. Expansion and activation of CD4(+)CD25(+) regulatory T cells in Heligmosomoides polygyrus infection. Eur J Immunol. 2007;37:1874-86.

30. Hewitson JP, Filbey KJ, Grainger JR, Dowle AA, Pearson M, Murray J, et al. Heligmosomoides polygyrus elicits a dominant nonprotective antibody response directed against restricted glycan and peptide epitopes. J Immunol. 2011;187:4764-77. 